\section{Renown in theory}

\section{Steven Shapin}

The Pasteurization of France. By Bruno Latour. Translated from the French by Alan Sheridan and John Law. Harvard University Press: 1988. Pp.273. \$30. To be published in Britain on 9 December, f23.95.

Historians will not turn to this text for a definitive account of Pasteur's research and its institutionalization. (A long-awaited book by G.L. Geison will soon perform that function.) Latour is a philosophersociologist, and he uses historical material solely to illustrate a general theory of the nature of science, society and the relations between them. Indeed, Latour describes this volume as a "companion book" to the précis of his theoretical framework in Science in Action (see Nature 326, 754; 1987). Latour's divergent disciplinary allegiances are reflected in this new book's two radically different sections - one which belongs to a recognizably empirical 'social historical' genre, and a shorter, oracularly aphoristic 'philosophical' part written in an idiom that might best be described as a mixture of late Wittgenstein and high chutzpah: " "Everything is necessary' and 'everything is contingent' means the same thing - that is nothing"; "Knowledge does not exist - what would it be?".

In Latour's case, the audacity is justified. He is one of our least boring commentators on science and society. Everything he writes is provocative, important and worth the closest scrutiny. If he is right, all existing research into the nature of science and its social relations is wrong, and we had best start again with him as our guide. And if he is wrong, he is only strategically wrong, and we still benefit from the acuteness of his tactical analysis of scientific practice.

How did it come to pass that there is a street named after Pasteur in every town in France? More generally, how are we to account for the 'success' of any particular piece of science or technology? Is it sufficient to point to the genius of the individual Pasteur? No, that can't be right. That Pasteur was a 'genius' was precisely the outcome of the work of many others those who seized upon his work and declared him a 'genius'. Ideas do not diffuse of their own accord. They must be fetched and carried if they are to move. Thus, Latour points to the essential role of the pre-existing "hygienist" movement, with its talk of "contagion" and "morbid spontaneity", and its sanitary practices diffusely directed towards countless sources of environmental danger. Pasteur sought to interest them in his bacteriological ideas, and they were indeed interested, because pasteurism gave them a plan whereby they could mobilize their skills and concentrate their forces against just a few points through which environmental threats might pass.

Are we then to speak of the 'truth' or 'efficacy' of Pasteur's ideas if we want to explain the pasteurization of France? That also can't be right, Latour says, since it was because his ideas were seized upon by others and inserted into their routine practices that they came to be accounted 'true' and 'powerful'. Hygienists, seeing what they could do with Pasteur's ideas, immediately celebrated the certainty and validity of his experiments. But there were some, such as Koch and Peter, who resisted, pointing - with support from contemporary canons of scientific method to the "hasty generalizations" Pasteur made from a few experiments. Pasteur's

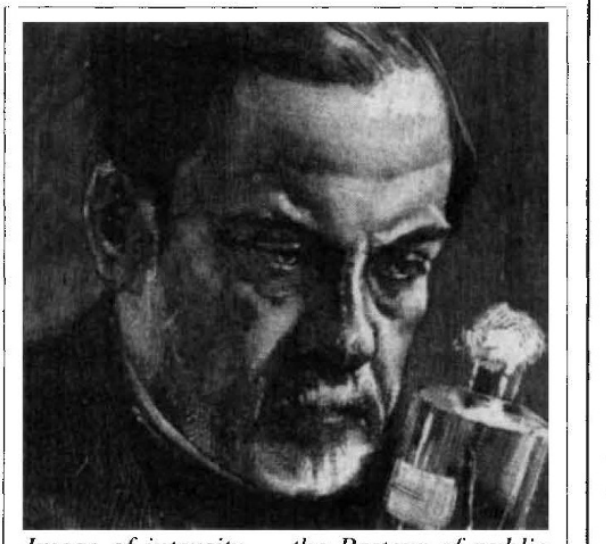

Image of intensity - the Pasteur of public fame. The picture is reproduced from the recent re-issue of René Dubos' Pasteur and Modern Science (Science Tech/Springer).

opponents were behaving no more unscientifically' than his supporters. Latour opposes realist and rationalist philosophies of science: 'truth' and 'power' are outcomes of what are usually called social processes; they can't be regarded as causes of scientific judgements.

France was not pasteurized through the inherent genius of the individual Pasteur nor because of the inherent truth of his ideas. Pasteurism was victorious insofar as its ideas and practices enlisted and were enlisted by numerous and powerful allies and insofar as they were made indispensable to others. Latour incisively analyses the processes by which pasteurians recruited their allies and inserted themselves into others' networks. Did farmers wish to prevent their cows from dying of anthrax, vignerons and brewers to make more reliable products, surgeons to heal their patients? Then they must acknowledge the existence of myriad microbes acting on them and their work. Who spoke for these invisible microbes? Pasteur and his colleagues. Those who wished to defeat the malevolent action of the microbes were obliged to pass through Pasteur's laboratory to accomplish their goals. The institutionalization of knowl- edge and practice is seen as the constitution of a new "obligatory point of passage" through which others must pass to do their work. Pasteur's laboratory was the place where his skills were most effective. By funnelling others' interests through it, Pasteur himself grew strong. Latour's analysis of the pasteurian circulation between field and laboratory and back again is a brilliantly innovative way of conceiving the institutionalization of science.

Conversely, some groups resisted Pasteur because they sensed that his skills and practices conflicted with their professional interests. Ordinary medical practitioners, for example, initially saw in Pasteur's methods and doctrines a "negation of medical work". Bacteriological concepts struck at the root of the relationship between doctor and individual patient, just as pasteurian stress on preventative measures directed towards populations conflicted with family physicians' emphasis on the cure of individual patients. Until the shift from preventative vaccines to curative sera, the pasteurians had not found a way to enlist such physicians as allies. And the physicians, "fighting to save [their] profession" and "to advance their own interests", found "disputable" and unscientific what hygienists found indisputable (pp. 117-127). Evaluations of the truth and usefulness of scientific claims are informed by evaluations of their relationship to existing skills.

Summarized this way, Latour's analysis seems both highly persuasive and in no way incompatible with British and American sociological and social historical perspectives developed over the past ten to twenty years by such scholars as Barry Barnes, H.M. Collins, G.L. Geison, Andrew Pickering and Charles Rosenberg. Yet, puzzlingly, Latour is extremely rude about work in this genre. Neither social context nor social interests can be used to explain the natural sciences; "social explanation" is, he pronounces, simply "obsolete" (pp. 255-256). The apparent reason for this judgement points to the originality of Latour's position as well as to the problems of using that framework to say anything about more traditional perspectives. The pasteurization of France was the creation of a new society - now containing the microbes for whom Pasteur spoke - as well as a new science. In Latour's lexicon, "interests" and "society" are effects of scientific work, and cannot be used to explain that work.

Indeed, Latour says that we must no longer speak of science and society but only of "stronger and weaker associations". Nor may we decide in advance what these networks consist of, whether they are made up of human or non-human agents. Everything can be what he calls an "actant" - men, machines, microbes. That some are said to possess agency, will and activity and others not is the result of 
attributional work in science. The distinction between men and the world on which they act is not to be a resource but a topic. Again, we cannot explain social action by referring to human beings as active and machines or bacteria as acted upon. This radically anti-reductionist and anti-realist stance arises from a French semiotic tradition that is neither well known in Anglophone scholarship nor adequately explained in this book. Is it a methodology and an analyst's conceit or is it an ontology? Is it a position about 'external reality' (as humble Anglo-Saxon empiricists think of it) or is it about the self-contained 'signifiers' of semiotic discourse?

One has to think that this semiotic perspective, when properly explained and understood, will resolve evident contradictions in Latour's work between programmatic injunctions and empirical practice. Thus, his abundant references to the professional "interests" of physicians are presumably not what they seem to be to Anglophone readers. And this new semiotic idiom will also explain how the use of such approved latourian locutions as "social groups", "networks" and "strong and weak associations" is different in kind to that of supposedly banned explanatory entities such as "social context" or "social interests".

Not just historians, sociologists and philosophers, but also scientists and members of lay society, have traditionally been interested in the relations between entities they call science and society. Latour instructs us that we have not just been giving bad answers but asking bad questions. The price of assimilating Latour's approach is that those who do so can have nothing to say to those who continue to be concerned about what they see as 'science-society' relations. The links between the academic science studies community, on the one hand, and scientists and laity, on the other, will be well and truly broken. The radical originality and wit of Latour's approach is hugely attractive. But many scholars will require a better understanding of the foundations of that work and a better sense of where it leads before they decide to pay the price.

Steven Shapin is Reader in the Science Studies Unit, University of Edinburgh, 34 Buccleuch Place, Edinburgh EH8 9JT, UK.

\section{Yummy, yummy?}

\section{John Yudkin}

The Paleolithic Prescription: A Program of Diet \& Exercise and a Design for Living. By S. Boyd Eaton, Marjorie Shostak and Melvin Konner. Harper \& Row: 1988. Pp.306. \$17.95*

MucH has been written about the possible causes of the rise in prevalence of coronary heart disease, diabetes and some sorts of cancer, mostly in the wealthier countries but now also being seen in parts of the Third World. One source of clues for the change in disease pattern lies in the comparison of the life-styles of the populations of places where the incidence of these diseases is very different (such as North America and Western Europe, against the non-industrialized nations of areas of Africa, South America and Asia).

Such comparisons have been the main reason for the widespread belief that at least some of the diseases of affluence are caused by diets low in fibre, because the diets of many countries that are largely free from these diseases are fibre-rich. This approach makes the assumption that the ideal life-style of the human race, and one to which we should return, is that of people living in pre-industrialized countries. But it is difficult to sustain such an argument in view of their lower stature,

* To be published in Britain in July 1989 by Angus \& Robertson, under the title The Stone Age Health Programme. Price will be $£ 4.95$, paperback only. style. They derive their evidence both from palaeontology and from the few tribes that still practise a largely hunting and gathering way of life. The authors elaborate their thesis in a splendidly readable, simple and lively style that seems most convincing.

It would be good to be able to add that the result is flawless exposition, but there are indeed flaws. Some of the suggestions are beside the point, such as avoiding oysters because they are rich in cholesterol; not many individuals regularly consume oysters as an important part of their diet. Some of the assertions are unproven and unlikely (that a low intake of fibre or of carotene can cause cancer), while others are quite unwarranted (that most people are short of calcium and that even those individuals that follow the "Paleolithic prescription" might be better off by taking vitamin supplements).

But the main flaw is the authors' failure to discuss those characteristics of human biology without which neither the Neolithic revolution nor the industrial revolution could have taken place. The invention of agriculture, with its revolutionary changes from a nomadic to a sedentary lifestyle, and from a diet rich in meat to one rich in starchy foods, was possible only because the human species is omnivorous, a quality that it shares with only a few other species such as the rat and the pig. The technological changes of the industrial revolution made it possible increasingly to produce new foods by separating the qualities of palatability from the qualities of nutritional value. Up to that time, it was true for all species that the foods they liked were the foods they needed: it is no longer true that, for human beings, palatability is an infallible guide to nutritional value.

It is also wrong to claim that the "Paleolithic prescription" is new, or even, as the publisher says, "groundbreaking". The idea has been around for at least 30 years; for example, it appeared in an article in The Lancet in 1956 and has been refined and elaborated in many later publications. We can now understand why our sugar consumption is so huge; it is not because, as the authors say, "developers of sugar beet and sugar cane plantations, together with industrialists, food technologists and advertisers, have encouraged" us to take more and more sugar-rich foods and drinks, but simply because we like them. Food manufacturers, technologists and others have devoted the same amount of energy and expertise to try and induce people to take food yeast; they have signally failed to do so simply because people don't like the taste of yeast. The omission of such considerations greatly detracts from the value of this book.

John Yudkin, 20 Wellington Court, London NW8 9TA, UK, is Emeritus Professor of Nutrition in the University of London. 